\title{
Effect of secretin and jejunal acidification on gastric and pancreatic secretion in man
}

\author{
S. J. KONTUREK \\ From the Institute of Physiology, Medical Academy, Cracow, Polard
}

SUMMARY The inhibitory effect of intravenous secretin and intrajejunal acid infusion on basal and pentagastrin-induced gastric acid secretion as well as the stimulatory influence of both infusions on pancreatic flow rate and bicarbonate output were compared in two groups of healthy subjects.

Secretin strongly inhibited basal acid output and slightly decreased pentagastrin induced gastric secretion.

Intrajejunal acid infusion did not affect the gastric secretion but resulted in an increase in pancreatic volume flow and bicarbonate output reaching about $40 \%$ of the pancreatic response to secretin ${ }^{1}$ infused intravenously in a dose of 2 units per kilogram per hour.

It is concluded that this provides evidence that secretin is a strong inhibitor of spontaneous gastric acid secretion and that acid in the jejunum causes the release of secretin in man.

It has been shown already that the acidification of the duodenum in man results in the inhibition of gastric acid secretion (Johnston and Duthie, 1966; Konturek, 1969) and in the stimulation of the pancreatic flow rate and bicarbonate output (Lagerlöf, Rudewald, and Perman, 1960) due to endogenous release of secretin.

Studies in animals have suggested that the area in which secretin can be released or isolated extends beyond the duodenum to the upper part of the intestines (Wertheimer and Lepage, 1901; Mellanby and Huggett, 1926; Weaver, 1927; Konturek, Dubiel and Gabryś, 1969). No study, however, has been undertaken to examine the influence of acid introduced into the jejunum on both gastric and pancreatic secretion in man.

The present report describes investigations on

'Produced at the GIH Laboratory, Karolinska Institutet Stockholm, Sweden. the effect of intravenous secretin or intrajejunal acid infusion on gastric acid secretion under basal conditions and in response to pentagastrin, as well as on the pancreatic flow rate and bicarbonate output in man.

\section{Methods}

Twelve male subjects aged from 25 to 38 years old and from 52 to $73 \mathrm{~kg}$ body weight, all volunteers, without any history or physical findings of gastrointestinal disease, were selected for the study. They were divided into two groups, $\mathrm{A} \rightleftharpoons$ and $B$, each containing six subjects. The effects of secretin or intrajejunal acid on basal secretion were studied in group $A$ and on pentagastrininduced secretion in group $B$. 


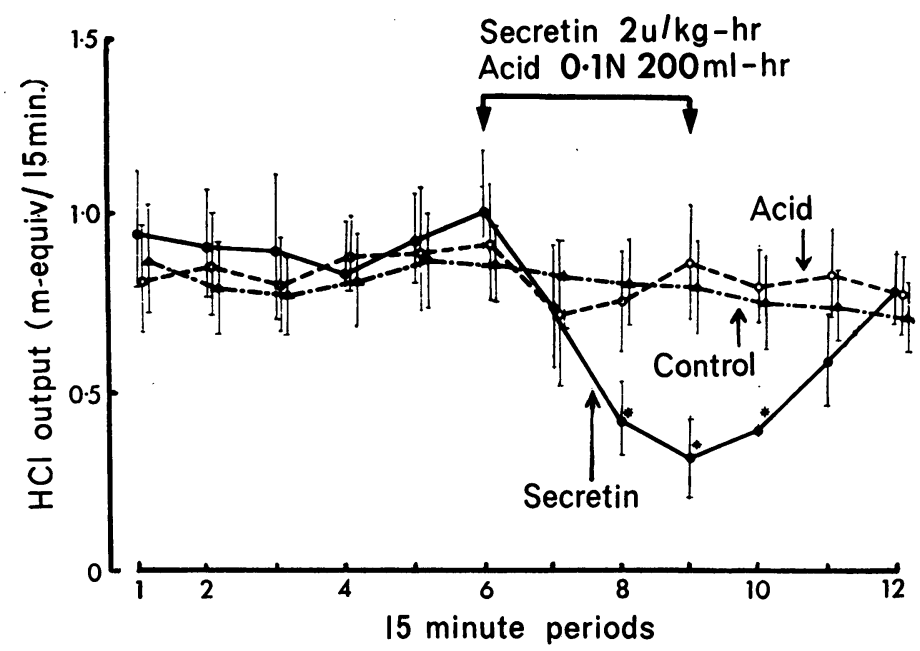

Pentagastrin $8 \mu \mathrm{g} / \mathrm{kg}-\mathrm{hr}$

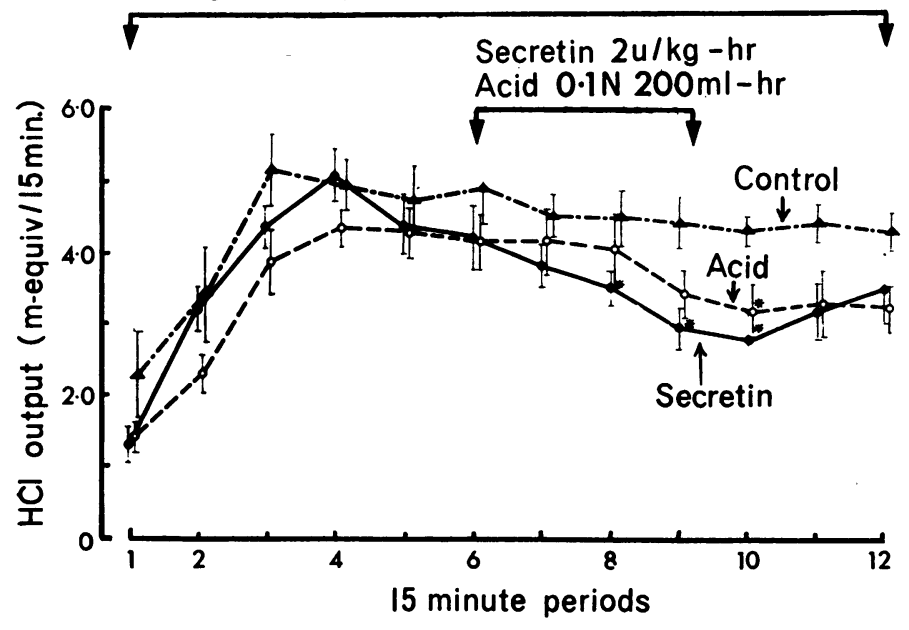

Fig. 1 The effect of intravenous secretin or intrajejunal acid on basal gastric acid secretion. (In this and subsequent figures each point represents the mean of six studies on subjects of group $A$ or $B$. The vertical lines indicate standard error of the mean.)

Fig. 2 The effect of intravenous secretin or intrajejunal acid on pentagastrin-induced acid secretion.

After an overnight fast two radio-opaque rubber tubes (no. $16 \mathrm{~F}$ ) were passed into the upper gastrointestinal tract under fluoroscopic control. The tip of the gastric tube was placed in the most dependent part of the stomach and used to aspirate the gastric content. The tip of the intestinal tube, containing a metallic chuck to facilitate passage through the pylorus, was introduced into the jejunum about $30 \mathrm{~cm}$ beyond the duodenojejunal flexure. The duodenal portion of this tube, provided with several sideholes opening in the middle and distal part of the duodenum, was used to collect the duodenal content. A fine polyethylene tube of $1.0 \mathrm{~mm}$ in external diameter, was fixed to the side of the intestinal tube with its tip resting in the jejunal loop near the end of the intestinal tube and employed to infuse saline or acid solution into the jejunum.

The gastric and duodenal juices were aspirated separately by a vacuum pump at a negative pressure of about $30 \mathrm{~mm} \mathrm{Hg}$ and collected in 15-minute batches. The acidity of the gastric juice was measured by titrating $0.2 \mathrm{ml}$ samples of gastric juice with $0.1 \mathrm{~N} \mathrm{NaOH}$ to $p \mathrm{H} \mathrm{7.0}$ using an automatic titrator (Autoburet, Radiometer, Copenhagen). Acid output was expressed in $\mathrm{m}$-equiv/15 minutes.

The bicarbonate concentration of the duodenal aspirates was estimated in $0.5 \mathrm{ml}$ samples by adding $1.0 \mathrm{ml}$ of $0.1 \mathrm{~N} \mathrm{HCl}$, boiling and backtitrating with $0.1 \mathrm{~N} \mathrm{NaOH}$ to $p \mathrm{H} 7.0$ (Autoburet, Radiometer). The output of bicarbonates was expressed in m-equiv/15 minutes.

\section{Test Procedure}

The gastric and duodenal contents were collected throughout the three-hour secretory tests performed either under basal conditions or during intravenous infusion of pentagastrin in a constant dose of $8 \mu \mathrm{g}$ kilograms per hour using a peristaltic pump (Unipan). Two plans were used in this study. In one, throughout the secretory test the jejunum was irrigated from a peristaltic pump at a constant rate of $200 \mathrm{ml}$ per hour. The perfusion fluid was $0 \cdot 15 \mathrm{M} \mathrm{NaCl}$ during the first six 15 -minute periods, then $0.1 \mathrm{~N} \mathrm{HCl}$ for four 15-minute periods, and then again $0 \cdot 15$ $\mathrm{M} \mathrm{NaCl}$ for the two last periods. In the control tests $0.15 \mathrm{M} \mathrm{NaCl}$ alone was infused into the jejunum throughout the secretory study. A small amount of phenol red $(200 \mathrm{mg} /$ litre $)$ was added to the fluid infusion and the samples of gastric or duodenal content were observed when titrated to $p \mathrm{H} \mathrm{7.0}$ for the presence of red coloration. No trace of this marker was found in gastric or duodenal collections, indicating that there was no reflux, back up through the duodenum or pylorus, of the fluid infused into the jejunum.

In the second plan, secretin in a dose of 2 units per kilogram per hour was added to saline infused intravenously at a rate of $30 \mathrm{ml}$ per hour throughout the test. The infusion of secretin was started after six 15-minute periods and continued for one hour.

The secretory studies were not carried out more frequently than twice a week.

The percentage of gastric acid secretion inhi- 


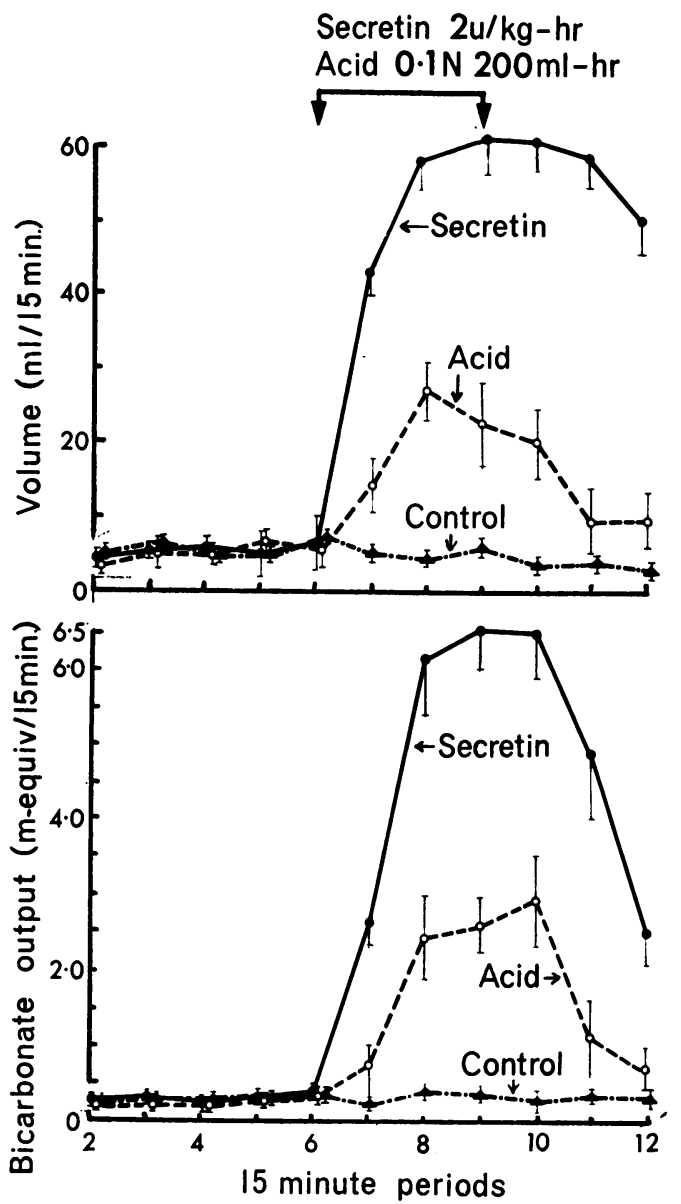

Fig. 3 Pancreatic volume flow and bircabonate output in response to intravenous secretin or intrajejunal acid infusion.

bited by infusion of intravenous secretin or intrajejunal acid was calculated from the difference between the mean acid output during the two 15-minute periods immediately preceding the infusion, taken as $100 \%$, and the mean acid output during the two last periods of infusion.

\section{Results}

Intravenous infusion of GIH secretin in a dose of 2 units $/ \mathrm{kg} / \mathrm{hr}$ produced an average inhibition of about $60 \%$ of basal gastric acid secretion in patients of group A. There was an average decrease of only about $30 \%$ in pentagastrininduced acid secretion caused by secretin in subjects of group B (Figures 1 and 2). A reduction in acid output following secretin was mainly

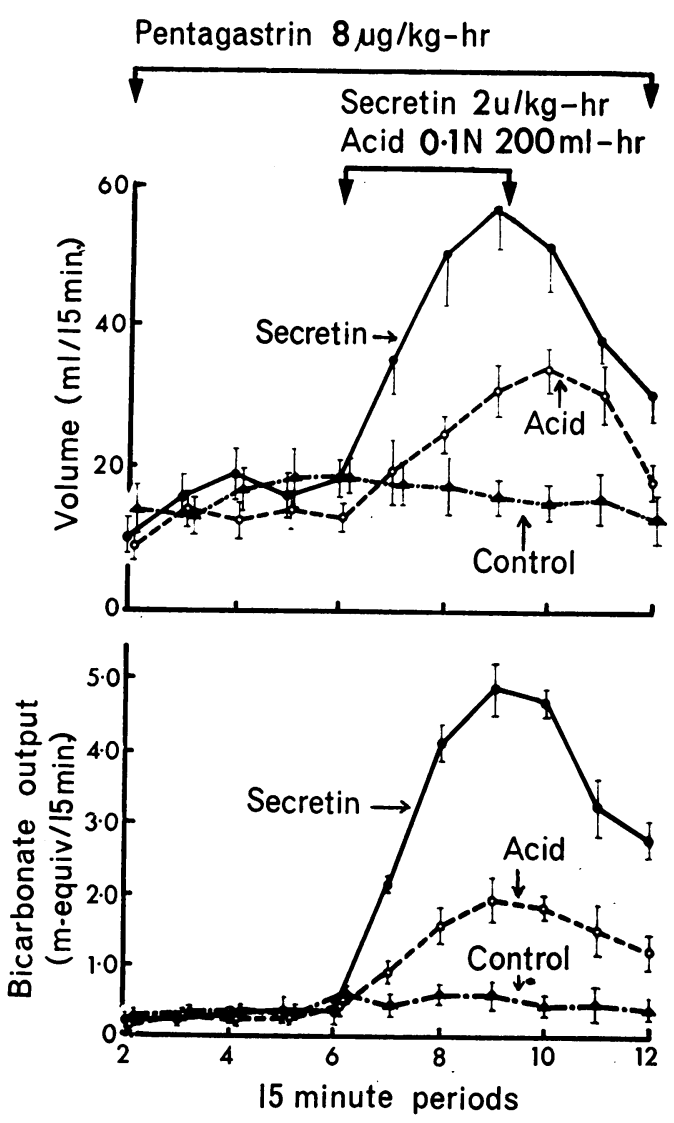

Fig. 4 Pancreatic volume flow and bicarbonate output in response to intravenous secretin or intrajejunal acid infusion, during intravenous infusion of pentagastrin.

due to the decrease of the acid concentration in gastric juice. This reduction observed in all subjects of group A and in five out of six subjects of group $B$.

The basal pancreatic flow rate and bicarbonate output in the subjects of group A was negligible. During pentagastrin infusion in a dose of 8 $\mu \mathrm{g} / \mathrm{kg} /$ hour, a slight increase in volume flow and in bicarbonate output was seen in the subjects of group B. In tests with and without pentagastrin, secretin produced an increase in volume flow and bicarbonate output. Both parameters of pancreatic secretion during secretin infusion followed the same patterns, reaching a peak within the first two 15-minute periods and then gradually decreasing. The intrajejunal acid infusion did not significantly affect the basal level and caused a slight reduction in pentagastrin-induced gastric acid secretion. 
Pancreatic flow rate and bicarbonate output during the jejunal acidification rose to a peak within the first two 15-minute periods of acid instillation into the jejunal loop and then showed a tendency to decline towards the basal level in both groups of subjects. The volume flow and bicarbonate output when acid was infused into the jejunum reached about $40 \%$ of the highest level attained with secretin stimulation (Figures 3 and 4).

\section{Discussion}

A number of studies in animals have shown that secretin is capable of inhibiting gastric acid secretion (Greenlee, Longhi, Guerrero, Nelsen, El-Bedri, and Dragstedt, 1957; Wormsley and Grossman, 1964; Johnson and Grossman, 1968; Vagne, Stening, Brooks, and Grossman, 1968; Konturek, 1969). Recent reports (Johnson and Grossman, 1968 and 1969) from Grossman's laboratory have demonstrated conclusively, in the dog, that secretin might account for all the inhibition of gastric acid secretion produced by duodenal acidification, and that this hormone is relatively more potent as an inhibitor of gastric secretion than as a stimulator of pancreatic secretion. They suggest that secretin is the only enterogastrone released by acid in the duodenum.

We have already shown, in cats, that gastric acid secretion is much more resistant to the inhibitory action of secretin (Konturek, 1969; Konturek et al, 1969b) and that this hormone cannot be entirely responsible for the inhibition of gastric secretion by acid in the duodenum. It was also demonstrated that secretin can be endogenously released by acid in the duodenum as well as in the jejunum (Konturek et al, 1969a). Although in the latter instance almost maximal pancreatic flow rate was attained no inhibition of gastric secretion was observed.

Previous studies in man (Kamionkowski, Grossman, and Fleshler, 1964; Dinoso, Chey, and Lorber, 1966; Wormsley, 1968a) showed that secretin does not invariably inhibit gastric acid secretion but that duodenal acidification resulted in rapid and strong inhibition of gastric secretion (Johnstone and Duthie, 1966; Konturek, 1969).

The present report shows that secretin in man inhibits the basal level and also to a lesser degree pentagastrin induced gastric acid secretion, whereas jejunal acidification does not affect gastric secretion but stimulates pancreatic secretion to about $40 \%$ of that attained with a submaximal dose of secretin.

The increase of pancreatic flow rate and bicarbonate output by acidification of the jejunum indicates that secretin can be released from this part of intestine. In man, therefore, as in animals, the area in which secretin is produced extends beyond the duodenum to the upper jejunum. The amount of secretin released by acid in the jejunum is relatively smaller and is capable of inhibiting considerably smaller pancreatic volume flow than that obtained by a submaximal dose of secretin.

This study shows disagreement with the results obtained in dogs (Johnson and Grossman, 1968 and 1969) and suggests that secretin in man, either released by acid in the jejunum or exogenously administered, is stronger as a stimulator of pancreatic secretion than as an inhibitor of gastric acid secretion.

The high cost of secretin precluded the use of larger doses in these trials, which might have displayed a stronger inhibitory action on gastric secretion. The dose used in this study however, has been shown by others (Isenberg and Grossman, 1969; Wormsley, 1968b) to induce almost maximal pancreatic secretion and thus, according to Grossman's criteria (Johnson and Grossman, 1968) may be considered as physiological.

Since side effects like nausea and retching were seen when it was attempted to introduce larger amounts of acid into the jejunum, it is not certain whether the endogenous release of secretin was complete. In addition, the physiological role of secretin released by acid in the jejunum is doubtful if under normal circumstances only the small upper part of the duodenum is acidified by gastric juice. In pathological conditions, eg after gastrojejunostomy, duodenectomy, or in hyperchlorhydria accompanying the ZollingerEllison syndrome, when gastric acid enters the jejunum, this part of the digestive tract might be a reserve source of secretin.

This work was supported in part by Research Grant TW-00217-01 from the National Institutes of Health, Public Health Service.

The author wishes to thank Professor E. Jorpes and Dr V. Mutt of the Grant Institutes of Health Laboratory, Karolinska Institutet, Stockholm, Sweden, for the generous supply of secretin and $\mathrm{Dr} J$. D. Fitzgerald from Imperial Chemical Industries, England, for the gift of pentagastrin (ICI 50123).

Please address correspondence to S. J. Konturek, MD, Institute of Physiology, Medical Academy Cracow, Grzegórzecka 16, Cracow, Poland.

\section{References}

Dinoso, V., Chey, W. Y., and Lorber, S. H. (1966). Effect of secretin on gastric secretory and motor function of the upper gastro-intestinal tract in man. (abstr.) Clin. Res., 14, 295.

Greenlee, H. B., Longhi, E. H., Guerrero, J. D., Nelsen, T. S., El-Bedri, A. L., and Dragstedt, L. R. (1957). Inhibitory effect of pancreatic secretion on gastric secretion. Amer. J. Physiol., 190, 396-402.

Isenberg, J. I., and Grossman, M. I. (1969). Comparison of subcutaneous and intravenous secretin in man. Gastroenterology, 56, 88-91. 
Johnson, L. R., and Grossman, M. I. (1968). Secretin: the enterogastrone released by acid in the duodenum. Amer. J. Physiol., 215, 885-888.

Johnson, L. R., and Grossman, M. I. (1969). Characteristics of the inhibition of gastric secretion by secretin. Amer. J. Physiol., 217, 1401-1404.

Johnston, D., and Duthie, H. L. (1966). Inhibition of histaminestimulated gastric secretion by acid in the duodenum in man. Gut, 7, 58-68.

Kamionkouski, M., Grossman, S., and Fleshler, B. (1964). The inhibitory effect of secretin on broth-stimulated gastric secretion in humans. Gut, 5, 237-240.

Konturek, S. J. (1969). The role of the intestines in the regulation of gastric secretion in man. (Polish). Pol. Tyg. lek., 24, 267-270.

Konturek, S. J., Dubiel, J., and Gabryś, B. (1969a). Effect of acid infusion into various levels of the intestines on gastric and pancreatic secretion in the cat. Gut, 10,749-753.

Konturek, S. J., Dubiel, J., and Gabryś, B. (1969b). Effect of exclusion, acidification, and excision of the duodenum on gastric acid secretion and the production of pentagastrininduced peptic ulcers in cats. Gastroenterology, 56, 703-710.

Lagerlöf, H. O., Rudewald, M. B., and Perman, G. (1960). The neutralization process in duodenum and its influence on the gastric emptying in man. Acta med. scand., 168, 269-284.

Mellanby, J., and Huggett, A. St. G. (1926). The relation of secretin formation to the entrance of acid chyme into the small intestine. The properties of secretin. J. Physiol. (Lond.), 61, 122-130.

Vagne, M., Stening, G. F., Brooks, F. P., and Grossman, M. I. (1968). Synthetic secret in: comparison with natural secret in for potency and spectrum of physiological actions. Gastroenterology, 55, 260-267.

Weaver, M. M., (1927). Distribution of pancreatic secretin in the gastro-intestinal tract. Amer. J. Physiol., 82, 106-112.

Wertheimer, E., and Lepage, L. (1901). Sur l'association réflexe du pancréas avec l'intestin grêle. J. Physiol. Path. gén., $3,689-702$.

Wormsley, K. G. (1968a). Gastric response to secretin and pancreozymin in man. Scand. J. Gastroenterology, 3, 632-636.

Wormsley, K. G. (1968b). Response to secret in in man. Gastroenterology, 54, 197-209.

Wormsley, K. G., and Grossman, M. I. (1964). Inhibition of gastric acid secretion by secretin and by endogenous acid in the duodenum. Gastroenterology, 47, 72-81. 